\title{
THE MORPHOLOGICAL STATUS OF ACCENT 2 IN NORTH GERMANIC SIMPLEX FORMS
}

Tomas Riad

\section{The meaning of markedness}

The issue of markedness of tonal accents in North Germanic (most Swedish and Norwegian dialects) has never been settled. For a long time, it looked like there was reasonable agreement that the distinction was privative and that it was accent 2 that was marked, accent 1 representing default intonation (Sweet, 1877:155, Elert, 1964:197, Haugen, 1967, Kristoffersen, 1993, Riad, 1998). Recently - and radically - one dissertation and a series of articles instead argue that it is accent 1 that is marked, while accent 2 is the default in words of the relevant shape (Lahiri, Wetterlin \& Jönsson-Steiner, 2005, 2006, Wetterlin, 2007). These are opposing views reached by people working within what is by and large the same general paradigm. How does that come to pass? The answer lies, it seems, in what expectations people ascribe to the notion of markedness, in particular whether representation is taken to be tied to markedness or not. ${ }^{1}$ For instance, the celebrated dissertation of Gösta Bruce (1977) proposed that the representation of the tonal accents was equipollent, that is, both accents contained a lexical part, manifested as an initial fall (HL). The difference was one of alignment of that fall to the stressed syllable, giving rise to the contrast (HL* vs. $\mathrm{H}^{*} \mathrm{~L}$ ). At the same time, Bruce clearly maintains that there is an asymmetry in that accent 2 is marked and accent 1 is unmarked (Bruce 1998). Unmarked accent 1 shows up in unintegrated borrowings (tango, bandy), and in the foreign accents of Swedish and Norwegian speakers. Thus, one could say that this account of the accents separates representation (equipollent) from markedness (asymmetric). Lahiri et al. (2005) have a similar view, but with the roles differently distributed. The marked member of the opposition is, in their view, accent 1 and the type of indicators of this marked status include exceptionality. What is exceptional, and that would include unintegrated loans, is also more likely marked. The marked feature is phonologically active and they capture that by claiming that accent 1 dominates, when lexically specified. While they acknowledge the fact that accent 2 is often tonally more contentful, they consider this a representational fact that has no

\footnotetext{
${ }^{1}$ For a recent discussion of different notions of markedness, cf. Haspelmath (2006).
} 
bearing on the markedness of the distinction. So in this case there are asymmetries on both counts, though unparallel ones.

My own view is that markedness should normally be reflected in representation for it to be meaningful. Differently put, a model that can connect representation to markedness will be more restrictive than one that doesn't, all things being equal. Thus, it would be in the courtyard of the defenders of the more abstract view to explain why it is alright for a lexical phonological specification not to be phonetically expressed, or why the unmarked member of an opposition would be phonetically more contentful than the marked member. The situation is in principle the same as that of so-called subtractive morphology, where e.g. plurals have a smaller structure than their singulars, in reverse with the common assumption of markedness (Golston \& Wiese, 1996). The controversy surrounding subtractive morphology rather highlights the theoretical issues at stake. While it might occur, and our grammars had better be able to handle them, it is not the common case.

\section{The tonal representation}

This paper, then, is in defense of what we might well call the traditional view, going back to Sweet (1877). It is in accent 2 that there is lexical content, and I shall assume that this, quite concretely, should be represented as a lexical word tone for simplex forms and many suffix morphemes. For the post-lexical word tone that shows up in nearly all compounds, the manifestation is phonetically similar, but the representation, of course, cannot be lexical in the sense that it is tied to individual morphemes. In the case at hand, markedness therefore means representation, and we can naturally connect the asymmetry of markedness (always assumed) with the privativity of representation (not always assumed). That seems to me like the most reasonable null hypothesis. In the clearest dialects it looks like all the tonal content of accent 1 is included in the tonal content of accent 2. The additional tonal information of accent 2 is coordinated with the stressed syllable. This causes the shared part to be shifted a little to the right in accent 2, as compared with accent 1 . This is illustrated in Figure 1.

Accent 1

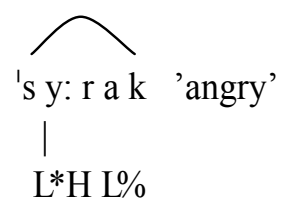

Accent 2

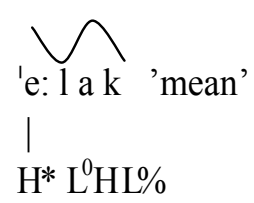

Figure 1. Schematic representations of Swedish accents in monomorphemic roots. Initial $\mathrm{H}^{*}$ in accent 2 is lexical, $\mathrm{LH}$ in both accents is the phrasal prominence tone, and final $\mathrm{L} \%$ 
is the boundary tone. The star indicates that the preceding tone is associated, and the raised ${ }^{60}$ indicates that such an association does not take place in accent 2 simplex forms.

The general pattern of the prominence tone being shifted to the right by the lexical tone in accent 2 comes back in dialect after dialect, and nowhere is the distribution the reverse. Even though the tonal content varies between dialects, the structure is remarkably stable and similar (cf. Riad 2006 for the typology).

The empirical domain for the discussion is a pattern that has hitherto not been recognized for its theoretical as well as descriptive interest. The pattern concerns the interaction of different desiderata in the grammar (not news in itself, of course), in the morphological derivation of forms that contain conflicting properties. The presence of unstressed syllables before the main stressed syllable (so-called anacrusis) favours accent 1, and the presence of a syllabic suffix usually correlates with accent 2 . Both properties can be isolated ( $k a^{1 \text { ' }} n o t$ 'canoe', ${ }^{21}$ hämt-a 'fetch'). When both come together in one and the same form, there is a conflict ( $k a^{\text {?' }}$ not- $a$ 'to canoe'). We look first at the descriptive generalizations and then turn to a discussion of the implications for the interpretation of tonal markedness in the lexicon.

\section{Accent 2 is a property of suffixes}

As is well known, accent 2 shows up in polysyllabic forms, where the primary stressed syllable is followed by another syllable. Monosyllables or final stressed words do not get accent 2, and this is entirely true of Central Swedish which is the dialect described here. ${ }^{2}$ Other prosodic shapes exhibit both accents and hence a contrast. An overview of the types of forms we shall look at is given in Table 1.

\footnotetext{
2 There are apocopating dialects that actually exhibit accent 2 in monosyllables, but often with some noticeable adjustments to accommodate the tonal material. See Lorentz (2008) for a recent discussion.
} 
Table 1. Prosodic shape and accent in Central Swedish.

\begin{tabular}{|c|c|c|}
\hline & Accent 1 & Accent 2 \\
\hline ' $\sigma$ & 'knöl 'hump' & -- \\
\hline$\sigma^{\prime} \sigma$ & ka'mel 'camel', gar'din 'curtain' & -- \\
\hline ' $\sigma \sigma$ & $\begin{array}{l}\text { 'tango, 'fänrik 'second lieutenant', } \\
\text { 'feg-is 'coward' }\end{array}$ & $\begin{array}{l}\text { 'sommar 'summer', 'byx-or } \\
\text { 'trousers', 'tvätt-a 'to wash' }\end{array}$ \\
\hline ' $\sigma \sigma \sigma$ & 'syfilis, 'Kanada & $\begin{array}{l}\text { 'löp-are 'runner', 'glad-are } \\
\text { 'happier' }\end{array}$ \\
\hline$\sigma^{\prime} \sigma \sigma$ & $\begin{array}{l}\text { bog'ser-a 'to tow', bo'lero, be-'tal-a } \\
\text { 'to pay' }\end{array}$ & ve'rand-a, go'rill-a \\
\hline$\sigma \sigma^{\prime} \sigma \sigma$ & $\begin{array}{l}\text { mili'tär-er 'militaries', kolli'sion-en } \\
\text { 'the collision' }\end{array}$ & kara'ok-e, pape'goj-a 'parrot' \\
\hline$\sigma \sigma^{\prime} \sigma \sigma \sigma$ & speci'ell-are 'more special' & speci'al-are 'a special' \\
\hline $\bar{\sigma} \sigma^{\prime} \sigma \sigma \sigma$ & traditio'nell-are 'more traditional' & $\begin{array}{l}\text { instrumen'tal-are ' instrumental } \\
\text { piece' }\end{array}$ \\
\hline
\end{tabular}

There are no difficulties to enumerate words in each of the cells. More than anything, Table 1 shows that, beyond the final stressed data in the first two rows, it is never going to be enough to just inspect surface prosodic properties to establish which words get which accent. The question is what other information we need. The important generalizations, to be motivated below, are as follows.

- Prosodic anacrusis (Auftakt) correlates with accent 1 , in the canonical case. ${ }^{3}$

- Syllabic suffixes correlate with accent 2 in canonical forms (Rischel, 1960, 1963), i.e. forms with initial stress and the suffix directly following in the post-tonic syllable (Riad, 2008).

The generalization that prosodic anacrusis yields accent 1 , everything else being equal, has its basis in underived forms like $a n^{11}$ sjovis, bo ${ }^{11}$ lero and Me ${ }^{11}$ lanchton. These invariably get accent 1 , given one recognizes the fact that etymologically monomorphemic forms are often reanalyzed as bimorphemic. Thus, it is clear that borrowed forms ending in [a] or [e] strongly tend to become segmented into morphemes $(-a,-e)$, with accent effects as a result. Other support for anacrusis correlating with accent 1 is found in compound accent in South Swedish (and very likely elsewhere in the dialect area). As Bruce (1974) has shown, South Swedish compounds with anacrusis in the first member invariably get accent 1 . The second generalization above is entirely straightforward since it is true of dialect after

\footnotetext{
${ }^{3}$ The number of unstressed syllables before the primary stress appears to be of no consequence for the capability to induce accent for a given suffix. It is the presence/absence of anacrusis that matters.
} 
dialect. The large morphological classes, manifested in suffixed derivations, constitute the bulk of the running exponents for accent 2 and they tend to be stable across dialects. Initial stressed monomorphemes is where dialects vary (Bruce, 1977:19).

Let us now turn to the actual interaction of anacrusis and suffixes. Table 2 contains a sorting of the suffixed words according to what accent they get in anacrusis forms. As it happens, a crisp pattern emerges, one where suffixes fall quite neatly into two classes with differing strength vis-à-vis anacrusis. In order to bring out the conflicting forces, Table 2 includes a ranking left-to-right, where the winning accent for each form is marked in bold. Defeated influences are shaded.

Table 2. Strong and weak suffixes meet prosodic anacrusis in Central Swedish.

\begin{tabular}{|c|c|c|c|c|}
\hline & & $\begin{array}{c}\text { "Strong" suffixes } \\
-a r e_{\mathrm{N}},-a_{\mathrm{N}},-e_{\mathrm{N}}, \\
-o r_{\mathrm{Pl}},-o r_{\mathrm{N}} \\
-s k a_{\mathrm{N}},-i g_{\mathrm{A}}\end{array}$ & $\begin{array}{l}\text { Prosodic } \\
\text { anacrusis }\end{array}$ & $\begin{array}{c}\text { "Weak" suffixes } \\
-(n) i n g_{\mathrm{N}},-a n d e_{\mathrm{VAN}}, \\
-a r_{\mathrm{Pl}},-a_{\mathrm{V}},-a r_{\mathrm{V}},-l i g_{\mathrm{A}}, \\
\quad-a r e_{\mathrm{comp}},-a s t_{\mathrm{sup}}\end{array}$ \\
\hline $\mathrm{a}$ & 'glad-are 'happier' & & & 2 \\
\hline $\mathrm{b}$ & speci'ell-are 'more special' & & 1 & 2 \\
\hline $\mathrm{c}$ & 'löp-are 'runner' & 2 & & \\
\hline $\mathrm{d}$ & speci'al-are 'a special' & 2 & 1 & \\
\hline e & bog'ser-a 'to tow' & & 1 & 2 \\
\hline$f$ & bog'ser-ing 'towing' & & 1 & 2 \\
\hline $\mathrm{g}$ & bog'ser-are 'tower' & 2 & 1 & \\
\hline
\end{tabular}

The comparative suffix -are yields accent 2 in initial-stressed ${ }^{21}$ glad-are 'happier', but when there is anacrusis, the result is always accent 1 with this suffix (speci ${ }^{1}$ ell-are 'more special'). Homophonous nomen agentis -are also yields accent 2 in initial-stressed ${ }^{21}$ löp-are 'runner', but also in the anacrustic form speci $^{21}$ al-are 'a special'. This is just a straightforward description of the factual distribution in this set of forms, and no assumptions regarding the lexical status accent 2 information need to be made at this stage. We see that, apparently, there are two classes of forms, defined by suffix, which react differently to the presence of anacrusis at the other end of the word. The pattern is particularly clear with the verb bog ${ }^{1}$ ser- $a$ 'to tow' and two derivations of it. The infinitive and all other verb forms ( bog $^{1}{ }^{1}$ ser-ar present tense, bog $^{1 /}$ ser-ande present participle, bog ${ }^{11}$ ser-at supine) get accent 1 and so does the nominalization bog $^{11}$ ser-ing 'towing'. The nomen agentis bog ${ }^{11}$ ser-are 'tower', however, gets accent 2 , as we have now come to expect. The latter pattern shows clearly that accent variation follows the suffix, rather than the root, and so, an analysis that tries to specify accent on the root of 
these forms or on the er-morph that is common in anacrustic verbs (and their derivations) will here run into trouble. Specifying accent 1 in this case will run into equally big problems, whether on roots or suffixes, since in non-anacrustic forms, all the suffixes exemplified in Table 2 correlate with accent 2 . A few examples occur in Table 1.

I contend from this interaction, that the information yielding accent 2 must be located in the suffixes and that this information gets blocked by anacrusis for some suffixes, while it prevails with other suffixes, also in the face of anacrusis. Whatever it takes to formalize this hitherto unobserved pattern, the fact that the lines are drawn up by suffixes, and the very fact that the suffixes induce accent 2 with different degrees of "strength", speak for a lexical representation of accent 2 , and one that is tied to suffixes rather than roots, in forms that have any morphological complexity.

Next, let us bring in two other types of data, namely forms with unstressed prefixes, and forms with two stresses (typically compounds).

\section{Prefixes and compounds}

The (normally) unstressed prefixes be- and för-instantiate anacrusis, by virtue of being unstressed, but they also bring morphological complexity into the picture. The tonal result is more homogeneous than with ordinary anacrusis, namely accent 1 in all simplex forms. So this particular type of anacrusis seems extra strong. Even stronger than that, however, is the so-called post-lexical accent 2, triggered by the presence of two or more stresses in a form. In Central Swedish, as in many dialects north of Skåne and east of East Norwegian (cf. maps in Riad, 2003, 2005, and 2008a), accent 2 is near-obligatory in compounds (more generally, in forms containing more than one stress). The geographic distribution as such has to do with the phonological structure of accent (Riad, 1998a, Riad \& Segerup, 2008) but the important fact here is that this type of accent 2 is motivated outside the lexicon. Any combination of stressed morphemes, whatever accent they each have in simplex form, will come out with accent 2 , when put together as a compound or derivation (e.g. suffixes -,dom, -, sam, -, aktig). The word tone then occurs on the first stress, and the phrasal prominence tone occurs on the last stress. Table 3 demonstrates the interaction of these two properties with the other ones. 
Table 3. Postlexical accent and prefixed forms in Central Swedish.

\begin{tabular}{|l|l|c|c|c|c|c|}
\hline & & $\begin{array}{c}\text { Two } \\
\text { stresses }\end{array}$ & $\begin{array}{c}\text { Pros. anac. } \\
\text { by prefixes } \\
\text { be- and } \\
\text { för- }\end{array}$ & $\begin{array}{c}\text { "Strong" } \\
- \text { are }_{\mathrm{N}}, \\
-e_{\mathrm{N}}, \\
-i g_{\mathrm{A}}\end{array}$ & $\begin{array}{c}\text { Pros. } \\
\text { anac. }\end{array}$ & $\begin{array}{c}\text { "Weak" } \\
-a_{\mathrm{V}}, \\
- \text { lig }_{\mathrm{A}}\end{array}$ \\
\hline a & be-'tal-a 'pay' & & $\mathbf{1}$ & & & 2 \\
\hline b & för-'akt-lig 'despicable' & & $\mathbf{1}$ & & & 2 \\
\hline c & be-'ständ-ig 'constant' & & $\mathbf{1}$ & 2 & & \\
\hline d & för-'räd-are 'traitor' & & $\mathbf{1}$ & 2 & & \\
\hline e & 'be-_led-_sag-a 'accompany' & $\mathbf{2}$ & & & & 2 \\
\hline f & 'för-,an-,led-a 'occasion' & $\mathbf{2}$ & & & & 2 \\
\hline g & 'mellan-,mål 'snack' & $\mathbf{2}$ & & & & \\
\hline h & 'järn-,vägs-,spår 'rail' & $\mathbf{2}$ & & & & \\
\hline i & be-'tal-ka,nal 'pay channel' & $\mathbf{2}$ & 1 & & & \\
\hline
\end{tabular}

Table 3 shows that there is interaction at the postlexical level. The prefixes beand för- are normally unstressed, and they always correlate with accent 1 (a-d), whether the suffix is weak $(a, b)$ or strong $(c, d)$. That already tells us that something other is going in here, beside simple, prosodic anacrusis. Now note that the same prefixes show up in stressed form in $(\mathrm{e}, \mathrm{f})$, where they correlate with accent 2. This is a marginal pattern, but it sheds some light on the relationship between the prefixes and the types of stem they attach to. In $(e, f)$ the prefixes have attached and incorporated to an extant compound. Prosodically, the result is a larger compound, where the prefix now forms its own prosodic word. Together with the more ordinary compounds in $(\mathrm{g}, \mathrm{h})$, these examples demonstrate the simple fact that the presence of two stresses entails accent 2 in Central Swedish. Indeed, when a prefixed form is part of a compound, yet unstressed as in (i), accent 2 also prevails. Here, the prefixed simplex form be'tal-constitutes the first half of the compound.

I will not discuss the prosodic structure in depth here (for discussion see Riad, 2008). Suffice it for present purposes to simply note the behaviour and draw out a few consequences of it. The prefixes be- and för-behave prosodically differently when they attach to a simplex form and to a compound, respectively. This shows that we are really looking at a dynamic prefixation rather than simple anacrusis here. ${ }^{4}$ Also, the stronger effect on accent of prefixed forms, as compared to other

\footnotetext{
${ }^{4}$ There is some variation in the pronunciations due to opaqueness, and most likely also to analogy. For instance, the för-forms appear to carry stress more readily, and that might be due simply to the fact that there is another, always stressed för-prefix meaning 'before' in the language.
} 
instances of anacrusis, tells us that there must be an important structural difference here. And we can now pin the accentual behaviour on that structural difference itself.

Lahiri et al. (2005:11) take the pattern in $(\mathrm{a}-\mathrm{d})$ to mean that the prefixes beand för-are lexically specified for accent 1 : Why else should they yield accent 1 in the face of suffixes that otherwise correlate with accent 2? I think this view is problematic not only because of the compound-incorporating pattern noted in $(\mathrm{e}, \mathrm{f})$. The fact is that there are no other prefixes like be- and för-that have the same properties, but without the accent behaviour. If there were, then the resulting accent 1 would look more like a lexical property of these prefixes. However, other prefixes are either stressed, or not morphologically and prosodically segmented from the stem. This shows in that e.g. prefixes like des- and trans- cosyllabify with whatever follows (de.s-in.fi.ce.ra, tran.s-ak.tion), in contradistinction to beand för-which are syllabified separately. ${ }^{5}$ Prefixes like des- and trans- differ also in that they need not be directly pretonic like be- and för-. The upshot is that the structural morpho-phonological difference itself can be made responsible for the accent behaviour, making it unnecessary to posit direct lexical marking of accent 1, as proposed in Lahiri et al. (2005).

\section{Ramifications of the split}

The split into "strong" and "weak" suffixes is a descriptive fact. Naturally, a couple of questions present themselves. Why should there be a split like this? How is "strength" represented? A full answer to these questions require the collection of a broader range of data, more work on dialect comparison, and some adjustment of the theoretical tools. The split as presented so far is rather a simplification, and in the rest of this paper I will discuss further ramifications of the accent variation which point out the direction in which a deeper analysis is likely to take us.

\subsection{It's not random}

Two things indicate that the split isn't random: the internal properties of the suffixes and a brief look at North Swedish. In general, the strong suffixes are nominal in character and the weak ones are verbal. Consider Table 4 where the suffixes are listed in the two middle columns and examples given in the outer columns.

\footnotetext{
${ }^{5}$ This is testable only for consonant-final för-, in forms like för.e.na 'unite' and för.ä.ra 'bestow'.
} 
Table 4. Nominal and verbal in relation to strength

\begin{tabular}{|c|c|c|c|}
\hline & "nominal" & "verbal" & \\
\hline $\begin{array}{l}\text { dis }^{21} \text { trä-ing 'distracted } \\
\text { one' }\end{array}$ & - ing $_{\text {Nhypoc }}$ & $-(n) i_{\text {Nnom }}$ & $\begin{array}{l}\text { bogs- }{ }^{1} \text { er-ing 'towing' } \\
\text { pre }^{11} \text { dik-ning 'sermon' }\end{array}$ \\
\hline $\mathrm{ve}^{21}$ rand-a, -or & $-a_{\mathrm{N}} /-o r_{\mathrm{Pl}}$ & $-a n d e_{\mathrm{VAN}}$ & krum ${ }^{1 / b u k t-a n d e ~ ' f i d g e t i n g ' ~}$ \\
\hline $\mathrm{re}^{21} \mathrm{al}-\mathrm{e}, \mathrm{kara}^{21} \mathrm{ok}-\mathrm{e}$ & $-e_{\mathrm{N}}$ & $-a r_{\mathrm{Pl}}$ & an ${ }^{11}$ sjovis-ar 'anchovies' \\
\hline $\begin{array}{l}\text { pro }{ }^{21} \text { fess-or, } \\
\text { kon }{ }^{21} \text { dit-or 'pastry chef' } \\
\text { kan- }{ }^{21} \text { tor-er 'organists' }\end{array}$ & $-o r_{\mathrm{N}} /-e r_{\mathrm{Pl}}$ & $\begin{array}{l}-a_{\text {Vinf }} / \\
-a r_{\text {Vpres }}\end{array}$ & $\begin{array}{l}\text { rekvir- }{ }^{11} \text { er-a, -ar 'to order' } \\
\mathrm{ka}^{1}{ }^{1} \text { las-a, -ar 'to party' }\end{array}$ \\
\hline $\begin{array}{l}\text { profess- }{ }^{21} \text { or-ska 'p.'s } \\
\text { wife' }\end{array}$ & $-s k a_{\mathrm{N}}$ & & \\
\hline bogs- ${ }^{21}$ er-are 'tower' & $-\operatorname{are}_{\mathrm{N}}$ & $\begin{array}{l}- \text {-are }_{\text {comp }} / \\
\text {-ast }_{\text {sup }}\end{array}$ & $\begin{array}{l}\text { speci }^{11} \text { ell-are, } \text {-ast } \\
\text { 'more/most special' }\end{array}$ \\
\hline $\begin{array}{l}\text { ge }^{21} \text { lé-ig 'jellyish', } \\
\text { mo }^{21} \text { ras-ig 'morassy' }\end{array}$ & $-i g_{\mathrm{A}}$ & $-\operatorname{lig}_{\mathrm{A}}$ & $\begin{array}{l}\text { profess- }^{11} \text { 'or-lig 'professorial', } \\
\text { per }^{11} \text { son-lig 'personal' }\end{array}$ \\
\hline
\end{tabular}

The suffixes in the lefthand column are mostly nominal, while those in the righthand column are mostly verbal. However, nominal suffixes occur also in the righthand column, though they could be considered relatively "verbal". For instance, the -ing suffix is used as nominalization of verbal stems ( bog $^{1 \text { ' }}$ ser- $a$ 'to

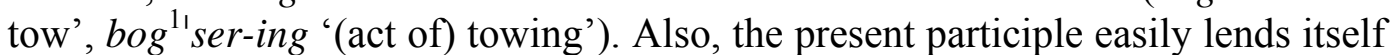
for use as noun or adjective, just like in English (krum ${ }^{1}$ bukt-ande 'fidgeting', $k a^{11}$ not-ande 'canoeing'). On the other side we have more nominal endings like nomen agentis -are ( bog $^{21}$ ser-are 'tower'), and person-denoting suffixes like -or (pro $\left.{ }^{21} f e s s o r\right)$ and -ska (profes ${ }^{21}$ sor-ska 'professor's wife'). There are also two adjectival suffixes, one weak ( $\mathrm{kam}^{1}$ 'rat-lig 'friendly') and one strong ( $g e^{21} l e ́-i g$ 'jellyish'). There is no obvious sense in which these diverge from each other on a nominal/verbal dimension. There are no verbal suffixes in the "nominal" column.

Another observation one might make is that suffixes sometimes stick together. Thus, the singular - $a$ and its corresponding plural -or seem to go hand in hand (formerly weak feminines), both being strong ( $\mathrm{go}^{21} \mathrm{rill}-\mathrm{a} /-\mathrm{or}$ ' $\mathrm{sg} / \mathrm{pl}$ '). The singular -e usually corresponds with plural -ar, but as it happens the set of words that end in $-e$ and have anacrusis appear not to belong to this class, indeed tend to lack a plural form altogether (guaca ${ }^{21}$ mol-e, $\left.k a r a^{21} o k-e\right)$. Intuitions regarding what plural they would get are weak, and the case can't be fairly tested.

The division of verbal and nominal suffixes that the weak/strong distinction appears to, by and large, abide by, shows up elsewhere in phonology. Kabak \& Plank (2007) enumerate a large number of cases where phonology seems to be implicated in word class distinction, and question whether the connection is real. Smith (2001) takes such correlations in Spanish and Japanese to mean that the noun/verb distinction should be analysed in terms of positional faithfulness, where 
nouns constitute the privileged class. We note here that while the correlation works in the right direction also for the case at hand, it will not reduce to the word class distinction, since the divide is not that coarse. The grammar would have to be relativized to handle that in equal degree. A brief look at North Swedish only strengthens the perspective on the variation as fine-grained and largely suffix-true.

\subsection{North Swedish}

Figure 2 illustrates the positioning of suffixes along the strong/weak dimension in one variety of North Swedish (Västerbotten) in comparison with Central Swedish. ${ }^{6}$

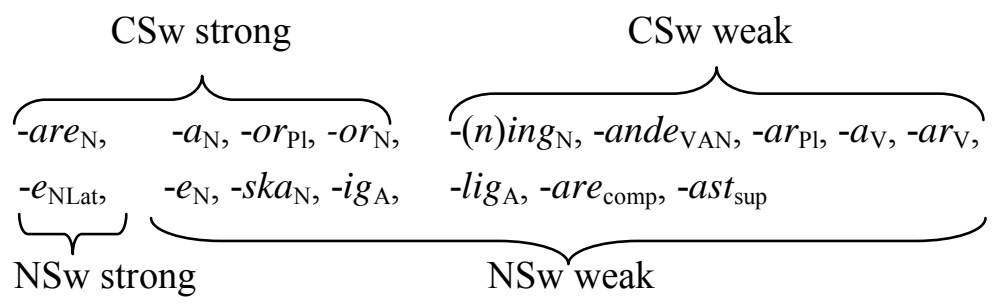

Figure 2. Strong and weak suffixes in Central Swedish (CSw) and North Swedish (NSw).

It is well-known that accent 1 is more common in North Swedish than in Central Swedish and the fact that only very few suffixes are strong in North Swedish is one source of this. Preliminary observations indicate that the $e$-suffix is further divided in North Swedish, between Latinate-sounding words (reale, promille) and other words (karaoke, guacamole). This looks like a finer tuning of the notion of strength, one that is located inside a suffix.

\subsection{Finer splits and analogy}

The complexity of the accent distribution becomes even more evident when we recognize that there are some splits that relate to a struggle between the entrenchment of patterns in the grammar and the productivity of some suffixes.

The relevance of productivity is evidenced by the verbal forms. Verbal suffixes are generally weak, but their productivity can sometimes occasion greater strength. Thus, when we construct new, anacrustic verbs, these will, it seems, be able to get accent 2 (with some optionality). Crucially, this only concerns verbs that don't belong to the most productive class among the anacrustic verbs (-eraverbs). So, in a putative form like kara ${ }^{21} o k-a$ 'to do karaoke', accent 2 is quite possible. However, an established form like $k a^{11} l a s-a$ 'to feast on' gets accent 1 , while a semi-established form $\mathrm{ka}^{1 / 21}$ not- $a$ 'to canoe' vacillates regarding accent.

\footnotetext{
${ }^{6}$ The NSw information is based on personal communication with Görel Sandström.
} 
These verbs tend to have a slightly hypocoristic or at least neologistic ring to them. However, any form - neologism or not - that includes the morph -er-, must get accent 1 (onomatopoeti ${ }^{11}$ sera 'to onomatopoeticise', cf. bog ${ }^{11}$ s-er-a 'to tow').

So this pattern tells us that the degree of entrenchment of a pattern is of some importance, and the regularity appears to be that accent 2 is in general stronger in productive patterns. However, regular base properties tend also to interact with suffixes in a regular way. On top of this, there are most likely real analogical effects. There is a suffix -ska which means 'female belonging to the root meaning' and it strongly induces accent 2 in forms like profes ${ }^{21}$ sorska 'wife of professor', $r^{2} k^{21}$ torska 'wife of headmaster', fran ${ }^{21}$ syska 'French woman and itali ${ }^{21}$ enska 'Italian woman'. However, there is another suffix -(i)sk which is adjectival and which in the weak form and in the plural overlaps with the female denoting nominal suffix, viz. in forms like itali ${ }^{1}$ enska 'Italian, adj.', ameri ${ }^{11} k a n s k a$ 'American, adj', $k u^{11}$ banska 'Cuban, adj.'. As it turns out, in a phrase like en itali $^{1 / 2}$ enska i Paris 'an Italian woman in Paris', either accent is possible, while accent 2 would be expected. This is, I think, not due to ambiguity on the part of the status of the nominal suffix as weak or strong, but rather to the analogical influence of the adjectival ending, which is homophonous and semantically not too distant. When the distance is greater, e.g. as between nomen agentis -are and comparative adjectival -are, there is no trace of such interference. In a fuller investigation of the interaction, other such dependencies could be expected to surface.

\subsection{A case of "superstrength"}

Another pattern concerns polysemy, alternatively the split of derivational suffixes. There is a hypocoristic suffix -ing beside the regular nominalising -ing. ${ }^{7}$ The nominaliser, that always relates to verbs, is clearly weak and yields accent 2 only in canonical forms with initial stress ( ${ }^{21}$ cykl-ing 'bicycling'). The hypocoristic -ing typically takes adjectives as base, e.g. ${ }^{21}$ snygg-ing 'handsome one', ${ }^{21}$ dumm-ing 'stupid/mean one', ${ }^{21}$ blek-ing 'pale one', and so on. This suffix, still a nominaliser, but with a narrow and productive meaning, is in fact strong, as emerges from the few anacrustic adjectives there are: ner ${ }^{21} v o ̈ s-i n g ~ ' n e r v o u s$ one', dis ${ }^{21}$ trä-ing 'distracted one', $c i^{21}$ vil-ing 'civil (non-military) one'. ${ }^{8}$ What's more, and what's quite unexpected given the pattern in Table 3 is that accent 2 prevails also in two hypocoristic -ing-derivations containing the unstressed prefixes: $B e-{ }^{1}{ }^{1} k v a ̈ m$ 'comfortable; lazy' and för- ${ }^{1}$ näm 'noble; snotty' come out as be- ${ }^{2} k v a ̈ m-i n g ~ ' l a z y$

\footnotetext{
${ }^{7}$ Accent 1 occurs also in relatively recent English borrowings ending in -ing, which often develop a parallel Swedish correspondent with -ning ( ${ }^{1}$ mobbing vs. ${ }^{21}$ mobb-ning). These are best analyzed as monomorphemes with no internal structure, for there is no evidence for productivity.

${ }^{8}$ Thanks to Cecilia Falk for pointing these out to me.
} 
one', för- ${ }^{21}$ näm-ing 'snotty one'. The fact that the prefixes can be overridden, in these cases, must be connected to the fact that the base is non-verbal, but also to the fact that the forms as such are neologistic (though clearly acceptable). Only under these circumstance can hypocoristic -ing show this "superstrength". There is another prefixed form be- ${ }^{1}$ kant-ing 'acquaintance' which is an established form unlike the two other, and which has accent $1 .{ }^{9}$

\section{Conclusion}

In this article, I have presented a general argument in support of the view that accent 2 is the marked member of a privative opposition, and that the lexical information instantiating the accent (together with phrasal intonation, obviously) most often resides in suffixes. The argument is supported by the hitherto undescribed distribution of accent in forms that contain two conflicting properties, one the one hand anacrusis, on the other hand suffixes that correlate with accent 2 in initial stressed forms. The result was, clearly, that the accent variation follows the suffixes rather than the roots or stems, yielding two major groups ("strong" and "weak") as well as a couple of minor, but dramatic, patterns. Beyond these simplex patterns which involve lexical accent, there is a distribution of accent relating to post-lexical constellations of morphemes such as prefixation to verbal roots, and prosodically driven accent 2 in forms containing more than one stress.

\section{Acknowledgements}

This research was funded by the Knut and Alice Wallenberg foundation through the Swedish Academy, herewith gratefully acknowledged. I would like to thank Sara Myrberg, Görel Sandström, Josefin Bloch and Jan Svanlund for discussion of the content and help with the collection of data.

\section{References}

Bruce, G. (1974). Tonaccentregler för sammansatta ord i några sydsvenska stadsmål. In C. Platzack (Ed.), Svenskans beskrivning 8, 62-75.

Bruce, G. (1977). Swedish word accents in sentence perspective. (Travaux de l'institut de linguistique de Lund 12) CWK Gleerup, Lund.

Bruce, G. (1998). Allmän och svensk prosodi. Praktisk Lingvistik 16. Lund University.

Elert, C.-C. (1964). Phonologic studies of quantity in Swedish based om'n material from Stockholm speakers. Almqvist \& Wiksell, Uppsala.

\footnotetext{
${ }^{9}$ It is a little unclear what the base is. Bekant is both an adjective and a noun.
} 
Golston, C. \& R. Wiese (1996). Zero Morphology and Constraint Interaction: Subtraction and Epenthesis in German Dialects. In G. Booij \& J. v. Marle (Eds.) Yearbook of Morphology 1995, 143-159.

Haspelmath, M. (2006). Against markedness (and what to replace it with). Journal of Linguistics 42, 25-70.

Haugen, E. (1967). On the rules of Norwegian tonality. Language 43, 185-202.

Jahr, E. H. \& O. Lorentz (Eds.) (1983). Prosodi/Prosody. (Studies in Norwegian Linguistics 2) Novus, Oslo.

Kabak, B. \& F. Plank. 2007. The role of phonology in word class distinction. Handout, ALT 7, Paris September 2007.

Lahiri, A., A. Wetterlin \& E. Jönsson-Steiner (2005a). Lexical Specification of Tone in North Germanic. Nordic Journal of Linguistics 28, 61-96.

Lahiri, A., A. Wetterlin \& E. Jönsson-Steiner (2006). Scandinavian lexical tone: prefixes and compounds. In G. Bruce and M. Horne (eds.), Nordic Prosody IX, pp. 167-173. Lund: Peter Lang.

Lorentz, O. (2008). Tonelagsbasis i norsk. Maal og Minne 1 (2008), 50-68.

Riad, T. (2003). Diachrony of the Scandinavian accent typology. In P. Fikkert \& H. Jacobs (Eds.) Development in Prosodic Systems, pp. 91-144. (Studies in Generative Grammar 58). Berlin/New York: Mouton de Gruyter.

Riad, T. (2005). Historien om tonaccenten. In C. Falk \& L.-O. Delsing (Eds.) Svenska språkets historia 8, pp. 1-27. Studentlitteratur, Lund.

Riad, T. (2006). Scandinavian accent typology. Sprachtypol. Univ. Forsch. 59.1 (STUF), 36-55.

Riad, T. (2008a). "Börk börk börk. Ehula hule de chokolad muus". Språktidningen nr 2, 2008, 34-39.

Riad, T. (2008b). Prosodi i svenskans ordbildning. ms. Stockholm University.

Riad, T. \& M. Segerup (2008). Phonological association of tone. Phonetic implications in West Swedish and East Norwegian. Proceedings Fonetik 2008, Göteborg, 93-96.

Rischel, J. (1960). Über die phonematische und morphophonematische Funktion der sogenannten Worttöne in Norwegischen. Zeitschrift für Phonetik und allgemeine Sprachwissenschaft 13, 177-185. (Norwegian translation printed in Jahr and Lorentz 1983.)

Rischel, J. (1963). Morphemic tone and word tone i Eastern Norwegian. Phonetica 10, 154-164. (Reprinted in Jahr and Lorentz 1983.)

Sweet, H. (1877). A handbook of phonetics. Oxford.

Wetterlin, A. (2007). The Lexical Specification of Norwegian Tonal Word Accents. PhD diss. University of Konstanz.

Wetterlin, A., A. Lahiri \& E. Jönsson-Steiner (2007). Tones and loans in the history of Scandinavian. In T. Riad \& C. Gussenhoven (Eds.), Tones and Tunes, volume 1. Typological Studies in Word and Sentence Prosody, pp. 353- 
375. (Phonology and Phonetics. Series editor: Aditi Lahiri) Berlin and New York: Mouton de Gruyter. 